Molekülspektren und ihre Anwendung auf chemische Probleme

Von Prof. Dr. H. Sponer. 1 : Tabellen. Pp. vi+154. 17.60 gold marks. Teil 2 : Text. Pp. xii +506. 37.80 gold marks. (Struktur und Eigensehaften der Materie, Bd. 15, 16.) (Berlin : Julius Springer, 1935-36.)

Thene is a good deal to be said in favour of the manner in which Prof. Sponer has arranged the material which he discusses in these two books. The first is really an appendix or collection of results for use in conjunction with the description of the applications of band spectra to chemical problems in part 2, and consists of a series of tables of the terms of spectra emitted by polyatomic molecules. Similar tables were, of course, given in Jevons's "Report on Band Spectra" for diatomic molecules, but the Sponer collection for more complicated molecular systems is new, and the data for diatomic molecules have been brought up to date. While it appears unlikely that the descriptive matter in the five hundred page Part 2 will soon need serious revision, it should be a relatively easy matter to add fresh results in a new edition of the one hundred and fifty page Part 1.

Part 2 is intended to assist experimenters, and there is little attempt at serious mathematical treatment of the subject. It opens with a brief, but good, introduction to the older quantum theory of spectra and to the new quantum mechanics, and continues with an excellent survey of the several types of band spectra and their peculiarities. The main interest lies in the examination of the methods and results of band spectra measurement and the chemical and physical data which can be obtained from them, and in the discussion of their importance in problems of chemi. cal combination and valency. Considerable attention is paid to the methods by which molecular spectra are excited and to photo-chemical reactions. The book is bound to appeal considerably to chemists and to physicists who are interested in the applications of band spectra.

\section{Destiny and Disease in Mental Disorders :}

with Special Reference to the Schizophrenic Psychoses. By Prof. C. Macfie Campbell. (Thomas W. Salmon Memorial Lectures.) Pp. 207. (London: Chapman and Hall, Ltd., 1935.) 10s. 6d. net.

Prof. Macele Campbell, who is professor of psychiatry at Harvard University, gives us a very readable account of personalities struggling against the difficulties of their environment, particularly with reference to the schizophrenic psychoses, which are a particular type developing in early adult life. This comes as quite a relief when contrasted with lengthy dissertations on infected bowels and sinuses. We feel on reading all these books on mental disorder that the problem in many ways has not even yet been stated, far less grappled with. There are so many factors involved, and we know so little. The writer, however, points out the importance of the environment and its manifold reaction on personalities, many of which we feel were already psychopathic in build.

\section{Insect Enemies of Shade-Trees}

By Prof. Glenn W. Herrick. Pp. $x+417$. (Ithaca, N.Y.: Comstock Publishing Co., Inc., 1935.) 5 dollars.

The name of Prof. G. W. Herrick, of Cornell University, as a guarantee for a sound, trustworthy textbook is fully substantiated in the present volume. It brings together much scattered information regarding the insect pests of shade trees east of the Rocky Mountains and most of those on the Pacific coast. The economic values of each species of tree are discussed and the most effective control measures against their chief enemies are dealt with. For the most part, each species of tree, with its insect invaders, forms the subject of a separate chapter while, at the end of the book, pests of the smaller trees and shrubs, and some miscellaneous enemies, are dealt with collectively. In so far as certain of the species of insects mentioned are of European origin, the book will interest English readers, while the control measures advised are often applicable on this side of the Atlantic Ocean. The book is admirably printed with 331 clear text figures, which are mostly original. Considering the excellence of its general 'get up', the book is reasonably priced at five dollars.

\section{Hydrostatics :}

a Text-Book for the use of First Year Students at the Universities and for the Higher Divisions in Schools. By A. S. Ramsey. Pp. viii + 169. (Cambridge: At the University Press, 1936.) 7s. $6 d$.

THIs volume has been specially prepared for the use of first year students in universities and for pupils reading for scholarships in the higher divisions of schools. It is thus a companion volume to the author's books on dynamics and statics, which have been published in recent years. The course well covers the academic requirements in the subject, and includes some simple applications of the metacentre, together with a brief discussion on capillarity. A working knowledge of the calculus is assumed, and there are numerous exercises provided for the student, many of which are taken from Cambridge examination papers. Answers to these are given where necessary. The text is illustrated with clearly drawn diagrams and elegantly worked-out examples. The book is admirably suited to its purpose.

\section{Outlines of General Psychopathology}

By Prof. William Malamud. Pp. xiv +462 . (London : Chapman and Hall, Ltd., 1935.) 21s, net.

Prof. W. Malamud, who is professor of psychiatry in the State University of Iowa, gives a very readable and useful account of the principles of general psychopathology. We wish, however, that he had enlarged somewhat on the physiological concomitants: action currents, particularly the Berger rhythm, chronaxie, and the psychogalvanic reflex are all subjects about which the reader will want to know more than the author gives us - a mere page for the three.

The chapter on the psychopathological disturbances of sleep is very well done. 